\title{
QUEM TEM MEDO DE EUTERPE? \\ PARA UMA GENEALOGIA DOS \\ CURRÍCULOS DE MÚSICA EM PORTUGAL NOS SÉCULOS XIX E XX
}

\section{¿Quién tiene miedo a Euterpe? Hacia una genealogía de los currículos de música en Portugal en los siglos XIX y XX}

\section{Who's afraid of Little Euterpe? Towards a genealogy of the music curricula in Portugal in the inth and oth centuries}

Ana Luísa Fernandes PAZ

UIDEF. Instituto de Educação Universidade de Lisboa

Correo-e: apaz@ie.ulisboa.pt

Recibido: 30 de marzo de 20I9. Envío a informantes: 25 de abril de 2019.

Aceptación definitiva: Is de enero de 2020

Resumo: A história do currículo tem trazido algumas contribuições no sentido de pensar a criança do futuro que o Estado, através das instituições escolares, deseja e rejeita. Neste sentido, seria importante instaurar uma discussão acerca de uma das disciplinas menos estudadas, a Educação Musical. Mas ao invés de articular esta criança em devir tendo em conta apenas a disciplina de Educação Musical contextualizando-a no currículo do ensino infantil, primário, secundário, a predo articular com um outro currículo, quase sempre considerado à parte, porque abrange também uma contraparte adulta. Refiro-me aos currículos vocacionais e profissionalizantes do Conservatório e da Escola Normal. Julgo, deste modo, ter aqui encontrado um enclave a partir do qual se poderá tentar compreender o poder de Euterpe e os modos como se criam tipos de pessoas com destinos sociais altamente diferenciados a partir de uma mesma tópica, neste caso, a música.

Em Portugal, o Estado apodera-se do ensino vocacional de música em I835. A partir da formação do Conservatório de Lisboa (I836), inaugura-se uma linha que 
persiste praticamente intocada até hoje. Paralelamente, foram sendo criadas outras formas de sensibilização para a arte musical, com diferentes tentativas de instalar a educação musical no ensino primário durante o século XIX. Finalmente, no final deste século, iniciaram-se as formações nas escolas normais, e, consequentemente, nas escolas primárias. No início do século XX, inicialmente apenas para raparigas, iniciou-se a experiência de educação musical no âmbito do ensino liceal. Ao contrário do que acontecia no Conservatório, não se ensinava a compreender ou produzir música, mas a cantar em coro. Durante o Estado Novo, esta política foi incentivada. Ainda em 1968, iniciou-se uma política de democratização que segue até aos dias de hoje e que passou por substituir o canto coral pela educação musical e por encontrar formas de alargar as formações vocacionais a mais e mais pessoas.

Proponho assim uma análise crítico-genealógica que visa interrogar quem foi a criança de futuro desejada e rejeitada e qual o medo que se instalou nas sucessivas reformas curriculares que abrangeram a música.

Palavras-Chave: ensino de música; educação musical; séculos XIX e XX; Portugal; análise crítico-genealógica.

RESUMEN: La historia del currículo ha aportado algunas contribuciones para pensar el niño del futuro que el Estado, a través de las instituciones escolares, desea y rechaza. En este sentido, sería importante establecer un debate sobre una de las disciplinas menos estudiadas, la Educación Musical. Pero en lugar de articular este niño en desarrollo teniendo en cuenta solo la disciplina de la Educación Musical, contextualizándolo en el currículo de la educación infantil, primaria y secundaria, necesito articularlo con otro currículo, casi siempre considerado aparte, porque también incluye una contraparte adulta. Me refiero a los planes de estudio vocacionales y profesionales del Conservatorio y de la Escuela Normal. Creo que he encontrado aquí un enclave desde el que podemos intentar comprender el poder de Euterpe y las formas en que se crean tipos de personas con destinos sociales muy diferenciados a partir de un mismo tema, en este caso la música.

En Portugal, el Estado asumió la enseñanza profesional de la música en I835. Con la formación del Conservatorio de Lisboa (1836), se inaugura una línea que persiste prácticamente intacta hasta hoy. Paralelamente, se crearon otras formas de sensibilización al arte musical, con diferentes intentos de instalar la educación musical en la enseñanza primaria durante el siglo XIX. Finalmente, a finales de este siglo, la formación comenzó en las escuelas normales y, por consiguiente, en las escuelas primarias. A principios del siglo $\mathrm{xx}$, inicialmente solo para las niñas, comenzó la experiencia de la educación musical en el ámbito de la enseñanza secundaria. Al contrario de lo que ocurría en el Conservatorio, no se enseñaba a entender o producir música, sino a cantar en el coro. Durante el Estado Novo se fomentó esta política. Todavía en 1968 se inició una política de democratización que continúa hasta hoy y que supuso la sustitución del canto coral por la educación musical y la búsqueda de medios para ampliar la formación profesional a un número cada vez mayor de personas.

Así, propongo un análisis crítico-genealógico que pretende cuestionar quién fue el niño deseado y rechazado del futuro y cuál fue el miedo que se instaló en las sucesivas reformas curriculares que abrazaron la música. 
Palabras Clave: enseñanza de la música; educación musical; siglos XIX y XX; Portugal; análisis crítico-genealógico.

AвSTRACT: The history of the curriculum has brought some contributions in the sense of thinking the child of the future that the State, through the school institutions, wants and rejects. In this sense, it would be important to establish a discussion about one of the less studied disciplines, Music Education. Instead of articulating this child of the future considering the discipline of Musical Education with the others that make up the curriculum of nursery, primary, secondary education, I propose to articulate it with another curriculum, contained in Conservatory formations and of the Normal School, thus also covering its adult counterpart.

Here we find a possibility to understand the power of Euterpe and the ways in which types of people are created with highly differentiated social destinies from the same topical of music education. In Portugal, the State seized vocational music education in 1835 . From the formation of the Lisbon Conservatory (1836), a curricular tradition was inaugurated and has remained practically untouched until today. At the same time, other forms of awareness for musical art were created, with different attempts to install music education in primary education during the nineteenth century. Finally, at the end of this century, formation began in normal schools, and consequently in primary schools. At the beginning of the 20 th century, initially only for girls, the experience of musical education began in the scope of secondary education. Contrary to what happened in the Conservatory, one did not learn to understand or produce music, but to sing in chorus. During the Estado Novo, this policy was encouraged. In 1968, a policy of democratization began that has been going on until nowadays, replacing choral singing with musical education and finding ways to extend vocational training to more and more people.

Thus, I propose a critical-genealogical analysis that seeks to interrogate who was the child of the desired and rejected future and what fear was installed in the successive curricular reforms that covered music and the possibility for the unknown Little Euterpes to come.

KEY WORDS: music education; I9th and 2oth centuries; Portugal; critical-genealogical analysis.

\section{Introdução}

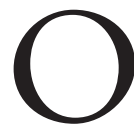

ARTIGO REVISITA a infância e juventude não permitida de uma Euterpe lusitana, instaurando um sentido das possibilidades de formação para um aluno de música no Portugal dos séculos XIX e XX. Euterpe, uma das nove musas da mitologia, consagrou-se a esta arte e foi usualmente representada com uma flauta. O seu nome continuou a ser invocado até ao século XX para representar a música e, no século XIX, muitas associações e coletividades musicais atribuíram-se o nome da musa. Se o semblante virtuoso de Euterpe é o resultado esperado do ensino de música, como foi Euterpe enquanto criança e jovem? 
Como não poderia ser esta musa da musicalidade? Haveria uma possibilidade de, no seu devir adulto, ela ter seguido um caminho que a levasse a assemelhar-se mais a Pã, o traquina deus dos bosques que também tocava alegremente flauta? Metáforas à parte, trata-se uma discussão acerca das crianças e dos jovens do futuro propostos nos currículos da educação formal, tanto para o ensino primário e secundário, através da disciplina de educação musical, como dos currículos do chamado ensino especializado de música, assegurado pelos Conservatórios e escolas congéneres.

Quando se pergunta quem são a criança e o jovem do futuro contidos neste currículo não se ignora a diferença abissal entre ambas as formações e seus planos curriculares. Nas línguas ibéricas distingue-se entre «ensino» - cingido às Escolas Especializadas ou formações equivalentes - e a "educação», expandida em diversas situações formais e não formais. O perfil de aluno é completamente diferente em ambas as propostas e essa separação encontra-se consagrada em letra de lei, apoiada por especialistas, como se lê nas palavras cuidadosas de Maria Brederode dos Santos. Enquanto membro do Conselho Nacional de Educação, ao propor recomendações de fundo ao governo, sublinhou que está a tratar «exclusivamente das aprendizagens artísticas que deverão constituir parte integrante da educação de todos e não do ensino artístico especializado» ${ }^{\circledR}$.

O questionamento começa, assim, por se radicar a este óbvio diferencial: será que estas propostas curriculares indiciam uma ou diversas crianças do futuro? A segunda questão que se coloca deriva diretamente deste primeiro plano e intenta averiguar o percurso destas crianças desejadas, questionando quem é criança excluída de toda e qualquer a paleta curricular.

Opto por realizar este ensaio historiográfico, de caráter crítico-genealógico, a partir de uma delimitação histórica que considera as fronteiras cronológicas de i835-1930. O período corresponde à implementação do modelo conservatorial moderno Português, que abarca a formação da disciplina de educação musical e sua implantação no ensino primário, normal e secundário ${ }^{2}$. Neste arco temporal de quase cem anos, estamos a considerar uma série de modificações no regime político, em que se inclui a passagem da monarquia para a República (I9IO), e seguidamente para a Ditadura (1926) a partir da qual se consagrou o regime do Estado Novo (1933), de cariz fascista.

Pretendo aprofundar o ensino musical a partir da tópica do currículo, sendo por isso a legislação, com as necessárias indicações sobre reformas, planos de estudo e outras diretrizes, a principal fonte utilizada.

Conselho Nacional de Educação: Recomendação n. i/20I3, «Recomendação sobre Educação artística», Diário da República, n. ${ }^{\circ}$ 19, 28 de janeiro de 2013, p. 4270 (sublinhado meu).

2 Refiro-me à Carta de lei de 2 de maio de 1878 da Direção-Geral de Instrução Pública, que Reforma a instrução primária e ao Decreto de 28 de julho de I880, que aprova o regulamento para a execução das leis de 2 de maio de I878 e de II de junho de I880, respetivamente sobre ensino primário e normal. 
ANA LUÍSA FERNANDES PAZ

\section{Pós-estruturalismo em currículo e história da educação e do ensino musical}

Perdem-se no alvor dos tempos as tentativas em definir o currículo, sendo defensável afirmar que se trata de um termo inerentemente impreciso ${ }^{3}$. Enquanto instrumento de planificação do Estado e uma matriz em torno da qual se organizam práticas docentes, pode com ele perguntar-se o que pode ser o presente e o futuro. Importa por isso, começar por recuperar a ideia de que o currículo é essencialmente um artefacto discursivo, no enclave de uma questão de «saber, poder e identidade ${ }^{4}$, uma vez que para o pós-modernismo, «o sujeito moderno é uma ficção»' e o currículo escolar pode, assim, ser considerado um dos instrumentos da sua construção e perpetração.

Uma perspetiva pós-estruturalista dos estudos curriculares tem assim sido cada vez mais alheia a articulações estritamente internas, e cada vez mais procurado compreender o currículo como um todo que opera na sociedade, muito para lá das paredes da escola, enfermado uma racionalidade própria e, por isso, podendo ser pensado enquanto «sistema de razão» ${ }^{6}$.

Ao mesmo tempo, a história da educação, tem buscado aprofundar o caso da educação e do ensino musical, embora ainda tibiamente. A delimitação institucional tem sido um marco de referência para a compreensão de aspetos pedagógicos. Começa por se destacar a fronteira entre os estudos que procuram recuperar os aspetos históricos do ensino especializado e os que buscam aprofundar o lugar da disciplina de educação musical na escola.

No primeiro caso, encontramos que é sobretudo a atual Escola Artística de Música do Conservatório Nacional ${ }^{7}$ a ser estudada nas suas em múltiplas diacronias ${ }^{8}$, sendo ainda de destacar os trabalhos exaustivos sobre o Conservatório de

JACKSON, P. W.: «Conceptions of curriculum and curriculum specialities», em JACKSON, P. W. (ed.): Handbook of research on curriculum, Nova Iorque, Macmillan, I992, pp. 3-40.

4 Silva, T. T.: Teorias do currículo: Uma introdução crítica, Porto, Porto Editora, p. I49.

Silva: Op. cit., p. II7.

6 Para uma resenha, Popkewitz, T. S.: «Curriculum study, curriculum history, and curriculum theory: the reason of reason», Journal of Curriculum Studies, vol. 4I, n. ${ }^{\circ}$ (2009), pp. 30I-319. Retirado de: https://doi.org/I0.I080/00220270902777021

Conservatório de Música (I835); Conservatório Geral de Arte Dramática: Escola de Música e Escola de Teatro e Declamação (I836); Conservatório Real de Lisboa (I840); Conservatório Real de Lisboa: Secção Musical e Secção Dramática (I90I); Conservatório Nacional de Lisboa: Secção Musical e Secção Dramática (I9Io); Conservatório Nacional de Lisboa - Secção Musical e Escola da Arte de Representar (I9II); Conservatório de Lisboa: Conservatório Nacional de Música e Escola da Arte de Representar (1919); Conservatório de Lisboa: Conservatório Nacional de Música e Conservatório Nacional de Teatro (1927); Conservatório Nacional: Secção de Música e Secção de Teatro (1930).

8 Rosa, J. C.: 'Essa pobre filha bastarda das artes' (1842-1862), Tese de mestrado, Lisboa, Universidade Nova de Lisboa, 1999; CosTA, J.: «O Conservatório Geral de Arte Dramática», em LessA, E. e SIMÕEs, M. (orgs.): I Encontro de História do Ensino da Música em Portugal, Braga, Universidade do Minho, 200o, pp. 75-I03. CosTA, J.: A Reforma do Ensino da Música no contexto das reformas liberais, Tese de mestrado, Braga, Universidade do Minho, 200o; GomEs, C.: Discursos sobre a 'especificidade' do ensino artístico, Tese de mestrado, Lisboa Universidade de Lisboa, 2002. 
Música do Porto9. Uma segunda linha de investigação historiográfica procurou compreender a edução e o ensino musical vinculada ao locus, nomeadamente a cidade de Lisboa ${ }^{\text {IO }}$.

Deste modo se foi criando o suporte para uma história crítica da educação onde a tópica da instituição dilui para dar lugar à análise de grandes invariantes e dispositivos institucionais, como sejam a especificidade do ensino da música e, de um modo global, a ideia de génio como articuladora das propostas de currículos

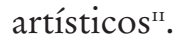

Este artigo procura assim traçar uma história do currículo pensando a criança e o jovem do futuro que o Estado, através das instituições escolares, deseja e rejeita, instaurando uma discussão acerca de uma das áreas disciplinares menos estudadas, a música. Ao invés de considerar a disciplina escolar com as outras que compõem o currículo do ensino infantil, primário, secundário, pretende-se articular esta criança e jovem em devir com um outro currículo, contido nas formações profissionalizantes e especializadas, quer do Conservatório, quer da Escola Normal. Aqui encontramos uma potência maior para compreender o poder do Estado e os modos como se criam tipos de pessoas com destinos sociais altamente diferenciados a partir de uma mesma tópica: Que medos provoca a pequena Euterpe? Esta pergunta, que guia toda a investigação, desdobra-se em muitas outras, das quais deixo apenas as mais significativas: Que perigos representariam uma infância e uma juventude malcuidadas do ponto de vista musical? Qual o devir adulto de uma criança ou de jovem cujo ensino musical falhou?

\section{Para uma análise crítico-genealógica}

Esta abordagem reivindica uma linhagem de análise crítico-genealógica, especialmente a partir das propostas de Michel Foucault na sua aula inaugural de 1970, depois publicada e traduzida para português com o título A Ordem do Discurso. A proposta inicial do filósofo é de um grande empreendimento teórico e empírico, em que a análise crítica do discurso se entrecruza com a genealogia, em que

9 Delerue, M. L.: O ensino musical no Porto durante o século XIX, Tese de licenciatura, Porto, Universidade do Porto, 1970; Caspurro, M. H.: O Conservatório de Música do Porto, Tese de mestrado, Coimbra, Universidade de Coimbra, 1992.

10 Rosa, J. C.: Struggling at the margins: Musical education in Lisbon 1860-1910, Tese de doutoramento, Londres, Royal Holloway - University of London, 2009.

" Martins, C.: As Narrativas do Génio e da Salvação, Tese de doutoramento, Lisboa, Universidade de Lisboa, 20II. Disponível em: http://repositorio.ul.pt/handle/I045I/5733. PAz, A.: Ensino da Música em Portugal (1868-1930), Tese de doutoramento, Lisboa, Universidade de Lisboa, 20r4. Retirado de: http://repositorio.ul.pt/handle/I045I/18383. Ó, J. R.; MARTins, C. S. e PAZ, A.: «Genealogy of history: From pupil to artist as the dynamics of genius, status, and inventiveness in art education in Portugal», em Popkewitz, T. S. (ed.): Rethinking the history of education, Nova Iorque, Palgrave, 2013, pp. 157-178. 
se devem questionar as «instâncias do controlo» e «analisar ao mesmo tempo as regularidades discursivas através das quais elas se formam» ${ }^{\mathrm{I2}}$.

A «exigência de método» de um projeto genealógico deve identifica alguns princípios metodológicos (inversão, descontinuidade, especificidade, exterioridade). Como veremos, o princípio da inversão é aquele que aqui mais se reclama, na medida em que a ideia de currículo para todos se mostrará um dispositivo de rarefação. Foucault empreende que «o princípio da inversão» é aquele que corresponde sobretudo à análise crítica, ao passo que a genealogia se debruça sobre os restantes princípios metodológicos ${ }^{13}$. Através da inversão, realiza-se um exercício ousado sobre o que não está lá, mas que ao mesmo tempo não é especulação e deriva de uma interpretação da fonte. Permito-me assim, a partir de uma figura abstrata e mitológica como Euterpe e a partir de categorias indefinidas e no limite da historicização de criança e de jovem, traçar uma interpretação para a história do aluno de música.

De igual modo, Foucault seleciona também quatro «noções» que devem servir de princípio regular para a análise (acontecimento, série, regularidade; condição de possibilidade). A condição de possibilidade - em que condições, em que contextos, em que temporalidades - se permitiu certo currículo musical é outra ideia central deste texto, onde não se pretende explorar o que realmente aconteceu, mas analisar nas práticas discursivas a potência deste devir contido nos currículos. Esta discussão parte assim da legislação que os enuncia e deixa de lado a heterogeneidade da série ${ }^{14}$.

Todo este projeto, que é assim, mais do que uma genealogia, uma análise crítico-genealógica, tem como mote pensar quais os medos - fundamentados ou não - estavam no âmago dos currículos musicais que foram sendo enunciados ao longo desta centúria, pensando por camadas arqueológicas de tempo os diferentes devires do sujeito-criança e jovem aluno de música.

\section{Se Euterpe crescer beata, marginal, ou desperdiçar o dom?: laicizar, conter, estatizar (1835-I868)}

O primeiro período identificado corresponde à implantação no país do moderno conservatório. Toda a Europa do Sul setecentista albergava instituições de ensino formal da música destinadas a órfãos, caso paradigmático dos ospedali venezianos, exclusivos do sexo feminino, e dos conservatorii napolitanos, apenas para meninos ${ }^{15}$. É este sistema que vai, em toda a Europa do Sul, justificar um ensino especializado, que funciona como um ramo à parte dentro do sistema

\footnotetext{
Foucault, M.: A Ordem do Discurso, Lisboa, Relógio d’Água, 1997, pp. 49-50.

Foucault: op. cit., pp. 44-45.

FOUCAULT: op. cit., p. 49.

is Rosa, J. C.: 'Essa pobre filha....', pp. I-3. LeÃo, R. S.: Considerações sobre diversos modelos de ensino de piano, Tese de mestrado, Almada, Instituto Piaget, 20I2, pp. 8-ı.
} 
educativo, ao passo que nos países anglo-saxónicos se optou por disseminar o ensino musical na educação regular, com o suporte de algumas escolas especializadas $^{16}$. Em Portugal, o final das guerras liberais terminou com a apropriação do património da Igreja Católica pelo Estado, procedendo-se em alguns casos ao saque e, o mais das muitas vezes, ao seu abandono. Da Sé da Patriarcal de Lisboa foram, em I834, retirados os instrumentos e a maioria dos professores que vieram abrir a Escola de Música do Conservatório Geral de Arte Dramática legislada em I836 $6^{17}$. No ínterim, procedeu-se à abertura de uma aula de Música na Real Casa Pia de Lisboa (decreto de I de janeiro de I835) e à subsequente transferência do Conservatório para a Real Casa Pia de Lisboa (decreto de 5 de maio de 1835). A Casa Pia era desde a sua fundação um dos símbolos máximos do Estado, ao albergar todos os órfãos e crianças desviadas e em risco de marginalidade ${ }^{18}$.

Esta trasladação natural do aluno de música órfão, desviante ou marginal, fazendo-o passar abruptamente entre o território clerical e o laico marca a dupla instauração de um governo liberal e do ensino estatal das artes liberais. Deste modo, a Rainha D. Maria e seu governo nomeiam o renomado escritor liberal, Almeida Garrett, para encabeçar uma série de medidas que poderiam dignificar a arte que mais considerada era naquele meio, o teatro. A fundação do Conservatório Geral de Arte Dramática, em I836, com as suas três escolas, demonstra que música e dança não passavam aqui de artes coadjuvantes.

No contexto da fundação da Escola de Música do Conservatório (1836) e da legislação e regulamentação que se seguiram, verificam-se as condições de possibilidade para a concretização dos primeiros currículos de ensino de música, onde se repercutiam diretrizes e práticas que acusavam a sua proveniência. $\mathrm{O}$ que nos dizem estes currículos sobre os medos do devir adulto de uma Euterpe que não fosse devidamente educada?

Em primeiro lugar, importa referir que todo o momento da fundação, que na legislação se expande sensivelmente entre I836 e I844, é marcado por uma clivagem não exclusiva das crianças e dos jovens com talento musical. A quem se destina o Conservatório?

Lê-se no Regimento de 27 de março de 1839 que são critérios de admissão «saber ler, e escrever, e ser dotado das faculdades físicas necessárias para o género de estudo, a que se dedica». Servirão de «impedimento exclusivo» os «vícios de conformação». Apenas se impõem algumas regras no que concerne ao chamado «Collegio do Conservatorio», e que não é mais do que a classe de música mantida na Casa Pia trasladada para a Escola de Música, composta por alunos internos,

16 Fernandes, D.; Ó, J. R.; Ferreira, M.; Marto, A.; Paz, A. e Travassos, A.: Estudo de Avaliação do Ensino Artístico, Lisboa, FPCE, 2007, pp. 205-ss. Disponível em: http://repositorio.ul.pt/ bitstream/I045I/550I/I/Relato\%CC\%8rrioEnsinoArti\%CC\% 8isticol.pdf.

${ }_{17}$ Vieira, E.: Dicionário biográfico de músicos portugueses, vol. I, Lisboa, Matos Moreira, I900, pp. I45-157.

${ }_{18}$ VAllera, T.: «Torna-te o que deves ser»: Uma história da polícia como genealogia da escola moderna (meados do século XVII - segunda metade do século XVIII), Tese de doutoramento, Lisboa, Universidade de Lisboa, 20I9. 
ANA LUÍSA FERNANDES PAZ

mantidos a expensas da instituição. O Colégio era, então, «destinado áquelles alumnos de ambos os sexos, que por seu raro talento, e falta de meios, merecem ser educados a expensas publicas» (art. 2. ${ }^{\circ}, \mathbb{S}$ único), mas o Conservatório em si não se destina, na sua origem, aos músicos inatos, apenas a garantir que o «raro talento» não seria desperdiçado por falta de condições propícias ao seu desenvolvimento. Acima de tudo, este talento, sempre que possível, seria detido por uma instituição estatal. Há aqui uma reverência e desejo de contenção de um dom divino ou que o Homem não poderia criar por si só, mas em que o Estado se atribui o papel de dominador dos mecanismos de contenção e devolução à sociedade.

O ensino musical não se destinava, de raiz, a nenhum perfil concreto, aproveitava de todos os mecanismos disponíveis que permitissem a contenção da tradição da música erudita ocidental do país, desígnio perfilado pelos Conservatórios desde a sua origem, em toda a Europa do Sul. O regulamento instituído pelo Decreto de 27 de novembro de I844 é absolutamente claro a este respeito, ao designar, logo à cabeça, o «objeto da Escola»: "A Eschola de Musica do Conservatorio é destinada pra o Estudo da Arte e Sciencia da Musica; para facilitar os seus progressos em geral, para conservar e propagar a sua pratica, para formar compositores, professores propriamente ditos, e Artistas para o serviço das Cathedrais, das Orchestras, e do Exercito das Bandas Militares». Esperava-se que a criação de Conservatório do Estado pudesse vencer todas barreiras institucionais, agrupando sobre si, como grandes tentáculos, as formas musicais que antes se dispersavam pela Igreja, Exército, Corte e famílias. Este gesto acompanha, assim, a estatização de toda a sociedade, cuja diversidade intrínseca das respetivas populações será um dos problemas mais dramáticos da instituição. Por sua vez, no ramo da educação primária, mantido completamente à parte, verifica-se, nas reformas de 1836 e I844, uma primeira tentativa de instituir o canto coral, embora as diretrizes não passassem de vagas indicações. Consabidamente, estas medidas foram apenas virtuais.

Vigorava neste período uma Euterpe virtuosa, que corresponde ao modelo clássico. Temia-se que a educação dos músicos não fosse concretizada devidamente por incúria do Estado e por não existirem mecanismos de apoio e contenção dos talentosos. Euterpe seria aqui forçada a escapar a um destino miserável, em que desperdiçaria os dons naturais entregando-se uma vida dissoluta, marginal, ou simplesmente pobre. Ou em que reconheceria esses dons, mas os entregaria às malhas da Igreja. Em suma, evita-se a todo o custo o advento de uma jovem Euterpe desviante, que deita a perder o tesouro da música erudita, que o Estado a tanto custo conquistou e glorificou como arte liberal e sua.

\section{Se Euterpe crescer desregrada, fora do seu meio?: instruir, educar, ensinar e burocratizar (I868-I898)}

O segundo grande tempo em que a infância e a juventude de Euterpe foi planificada pelos diferentes - e cada vez mais - poderes com interferência nos 
currículos escolares caracteriza-se pelo acordo sobre a natureza diferenciada do aluno de música e, por isso, corresponde a uma intensificação dos medos sobre o seu desregramento. Julgou-se desde então natural que só alguns indivíduos especialmente dotados prosseguissem estudos musicais. $\mathrm{O}$ mecanismo de rarefação do génio, que já circulava nas elites socioculturais, começa aqui a ser implantado nas políticas educativas, sendo deste modo um deslocamento e não uma condição de possibilidade posta de origem.

O decreto de 3I de dezembro de I868 orientava uma reforma a partir da recém-criada Direção Geral de Instrução Pública, que emergia no Ministério dos Negócios do Reino. Pela primeira vez, uma política educativa trazia a si todos os seus braços: instrução primária, incidindo em particular nas escolas normais, instrução secundária, Conservatório Real de Lisboa (ensino de música, teatro e dança), Academias de Belas Artes, instrução superior e bibliotecas públicas. Assimilados na mesma alçada da Instrução Pública, o ensino e a educação musical pareciam tender convergir, por muito diferentes que fossem os seus planos de estudo ou destinos sociais.

O princípio da fundação dos serviços que vieram a resultar na criação das grandes estruturas do Ministério da Educação só poderia ser o da burocratização, e à medida que a centúria de oitocentos decorria, ao mesmo tempo ganhava terreno a especialização do ensino musical ${ }^{19}$.

O crescimento paulatino das potencialidades da educação musical marca também a necessidade de realizar a incisão e separação entre os destinos de músicos e não-músicos, entre os que podem e os que não podem aceder a uma formação musical. O escopo desse muro realizou-se com o curso de formação de professores para o ensino primário. Durante os trinta anos seguintes, a abundante legislação não foi acompanhada de mudanças reais nas escolas do magistério, estipuladas desde a reforma da instrução primária de 1876 , pois somente o decreto de 28 de julho de 1880 consagrou o regulamento para o ensino do canto coral, mas nenhuma destas medidas teve impacto no desenvolvimento do ensino musical. $\mathrm{O}$ contingente populacional escolar desta época nunca atingiu as proporções desejadas em todos os setores, exceto no ensino especializado. O fundamental deste processo tinha sido iniciado: a separação. Podemos assim dizer que à medida que o sistema democrático se aprofunda, também o seccionamento da sociedade se complexifica e sistematiza.

Apesar das profundas reformas no ensino primário e normal que envidaram a criação das aulas de canto coral, no próprio Conservatório Real de Lisboa nada de marcante se assinala até $\mathbf{1 8 8 7}$. Bruscamente, a partir dessa data, sucedem-se as medidas legais tendentes a suportar uma reforma deste estabelecimento e, em breves três anos, sucede-se uma catadupa de diplomas, como sejam a Carta de lei de 25 de agosto de $\mathrm{I} 887$, que inicia a Reforma do Conservatório Real de Lisboa, e os decretos de 6 de dezembro de I888, e de 20 de março de i89o, que aprovam respetivamente o regulamento interno e geral da instituição. Nesta regulamentação,

19 Gomes: Discursos sobre a 'especificidade'... 
detalhadas condições educativas são explanadas pela primeira vez, nomeadamente, a «indicação expressa da duração, em anos, dos diversos cursos e disciplinas ${ }^{20}$. Podemos pensar nas razões que, para lá da burocratização do Estado e do desejo de organizar uma das suas instituições, podem ser inerentes a este súbito interesse legalista, em torno de quem poderia ser a pequena Euterpe desregulada.

Uma primeira evidência prende-se com o potencial marginalizante dos novos critérios de admissão. O capítulo dedicado a este critério sintomaticamente anuncia que «Todos os indivíduos de um e de outro sexo, nacionaes ou estrangeiros, podem ser admitidos á frequencia das aulas do conservatorio ${ }^{21}$. Colocando aqui em vigor o princípio metodológico da inversão, faz-se notar que esta expressão, «todos» - nunca antes vertido na legislação do conservatório - revela «uma declaração de compromisso nacional», que «atua como um sinal para um sistema

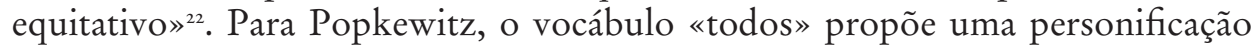
de «aspetos culturais tácitos em relação às qualidades e às caraterísticas de uma criança, estando fora de uma cultura e de um contexto». Por isso, «quando se fala dessa criança universal, alude-se também à criança que não atinge as expetativas e os benefícios», apontando, na verdade, para essa criança-outra em 'risco', que carece de «reparação e resgate». Nos modernos sistemas educativos, é esta criança excluída, que está «em risco ou em desvantagem» aquela que se torna «objeto de intervenção», por não corresponder à «criança universalizada» ${ }^{23}$. Com efeito, no ensino musical só muito tardiamente no século XIX se colocaram obstáculos à entrada e começam por ser anunciados pela formulação de que «todos» se poderiam matricular.

Nos artigos seguintes começam as especificações em que esta admissão poderia ser concedida, mas logo se verifica que, sendo o curso do conservatório dividido em curso geral e curso complementar, existem especificações para o curso obrigatório (Rudimentos) e para o curso geral, como sejam o comprovativo de idade, a certificação de habilitações ou o certificado de robustez física. Em termos estritamente musicais, somente na passagem para o curso complementar se coloca um impeditivo: «Serão unicamente admitidos á frequência do curso complementar, os alumnos que, durante o tirocinio do curso geral, ou nos exames d'este, derem provas distinctas e de evidente vocação artistica» (art. I2. ${ }^{\circ}$ ). O curso geral funcionava assim como aprendizado, onde só os mais aptos seriam recrutados para as fileiras mais exigentes.

Dez anos não tinham passado e já uma nova reforma era lançada. Logo a I3 de janeiro de I898, assinava-se o decreto que novamente reformava o Conservatório Real de Lisboa e a 28 de julho de 1898 , o regulamento do Conservatório Real de

20 Gomes, C.: Contributos para o Estudo do Ensino Especializado Musical em Portugal, Almada: Instituto Piaget, 2000, p. 20. Retirado de: http://dited.bn.pt/31617/2604/3154.pdf

${ }_{21}$ Decreto de 20 de março de 1890 art. $^{\circ}$ Io. $^{\circ}$

22 Pokewitz, T. S.: «A escolaridade e a exclusão social», em Paraskeva, J. (org.): A escolaridade e a exclusão social, Ramada, Pedagogo, pp. I2I-I22.

23 PoKewitz: op. cit., p. I22. 
Lisboa. Nada de fundamentalmente diferente se assinala, com uma segregação entre "curso geral, curso superior, curso especial», sem soluções inovadoras, e onde a principal medida foi a introdução de um inspetor.

Qual seria, assim, a principal linha de racionalidade que percorre este escopo legislativo do currículo conservatorial? À primeira vista, diríamos que a burocracia e a especialização do ensino dominam: todas as situações começam a ser previstas e para todos os casos existe uma prescrição. Entre estes, enuncie-se o dispositivo de avaliação que, pela primeira vez é alvo de uma aturada descrição.

Porém, um segundo olhar sobre a avaliação permite suspeitar que uma diferente racionalidade domina: a virtude do acaso. Com efeito, se é verdade que está prevista uma avaliação contínua, em que «O professor tomará diariamente nota das lições e exercícios escolares de cada aluno, qualificando o valor das lições» de acordo com uma «escala» ${ }^{24}$, no final remete-se para detalhadas indicações de sorteio, em ambos os regulamentos. Aí a sorte joga com Euterpe. Logo nos exames iniciais, «as provas práticas» de Rudimentos, e de Solfejo e Canto Coral, «são tiradas á sorte no acto do exame $»^{25}$. Nos exames finais de ano dos cursos gerais, as provas práticas passam a ser três: «I. ${ }^{a}$ Além dos exercícios de mechanismo, uma prova á vontade do jury; $2 .{ }^{a}$ Uma prova tirada á sorte, no acto do exame; $3 .{ }^{a}$ Uma prova á escolha do candidato (art $\left.5 \mathrm{I}^{\circ}{ }^{\circ}\right) »$.

Decisão do júri, escolha do aluno e sorteio são assim traves mestras do crivo que irá, ano por ano, separar os alunos com evidente vocação artística. Nos exames finais dos cursos gerais constam outras três provas práticas, realizadas à semelhança dos exames anuais e onde se inclui, desta vez, apenas o capricho júri e a sorte do candidato «Transporte de um pequeno trecho de musica, apresentado pelo jury, que o alumno executará no tom que lhe for indicado» e a «Execução de dois estudos tirados á sorte no acto do exame» (art. 52. ${ }^{\circ}$ ). Semelhante artifício se solicita para os cursos complementares, os que se destinavam já apenas aos 'virtuosi', e para os exames orais dos cursos de harmonia, neste caso, «respondendo o aluno em acto contínuo» à pergunta sorteada.

Por que razão se coloca o futuro de Euterpe sob o jogo caprichoso da sorte? Trata-se de um sistema que vigorou apenas neste curto período e que aponta para a garantia de justiça social, em que o acaso jogaria na constituição de uma Euterpe bem preparada e legitimamente reconhecida como tal.

Entretanto, se no capítulo do ensino primário e normal nada havia a assinalar, já no ensino secundário feminino começavam a despontar as primeiras experiências, nomeadamente na Escola Maria Pia (Lisboa), onde o regulamento de I89o previa uma aula de música.

Neste período, complexos dispositivos de segmentação e modelação foram implantados no currículo. Ao mesmo tempo que o Conservatório oferecia dois níveis de cursos, um aberto a «todos» e outro só aos de «virtuosidade», também se ia investindo numa democratização da educação musical, ainda vaga e pouco

24 Decreto de 20 de março de 1890, art. 32; Decreto de 28 de julho de 1898, art. 49.

${ }_{25}$ Decreto de 20 de março de 1890 , art. 50, \único. 
definida, por falta de professores e de alunos que a protagonizassem. Os medos sociais de que Euterpe não se desenvolvesse como se esperava tornavam-se mais complexos. Ela teria de ser cumpridora e virtuosa, não podendo ceder à relaxação e aos favores sociais. Arvoram-se, simultaneamente, margens que se vão ampliando à medida que o ensino de música se especializa e se expande, criando assento nas várias populações que, cada vez mais, procuram obter conhecimentos formais de música.

\section{Se Euterpe não for genial?: elitizar, aculturar, distinguir (I9OI-I930)}

O início do século Xx português marca a transição para a época de oiro do génio musical. Em todos os setores de educação se assinala um aumento dos que contactam, de modo mais ou menos aprofundado, com a arte musical.

Em I9oI, aquando da reestruturação do Conservatório Real de Lisboa sob o consulado de Augusto Machado na Escola de Música introduzem-se as primeiras medidas legais que advogam um corte fundo com o passado recente, lançando uma ponte direta com as fundações preconizadas por Almeida Garrett em I836. O Decreto de 24 de outubro de I9or fixava-se em duas traves, a fundação de um Teatro Lírico Português e a consagração do ofício do músico como arte e nunca como mero ofício. O preâmbulo citava Vincent d'Indy para frisar que «A arte musical não pode ser uma profissão; tocar bem um instrumento ou escrever corretamente uma cantata ou uma fuga, não é bastante para ser músico, para ser artista».

No dispositivo legal, estes princípios vinculavam-se a dois deslocamentos que temos acompanhado, a admissão dos alunos e a sua avaliação. A este respeito, o diploma marca uma continuidade ao considerar a matrícula de «Todos os indivíduos de ambos os sexos», mas apenas seriam admitidos aos «cursos superiores» os alunos com carta de curso geral. Observa-se a introdução de novos mecanismos de apoio à virtuosidade, nomeadamente de canto - área que passa a circunscrever duas disciplinas, a de canto individual e coletivo e a de canto teatral. «Para a frequencia da aula de canto individual e collectivo, podem ser dispensadas todas as habilitações aos candidatos que revelem aptidões muito excecionais e que se sujeitem a um exame especial» (art. Io. $^{\circ}$ ). Ao mesmo tempo, como se lê no preâmbulo, espera-se que «do Conservatório não saiam só pianistas». Com esta afirmação marca-se a crítica a um instrumento tendencialmente individualista, conotado com o salão burguês, e cada vez mais com a própria casa. Sublinha-se, assim, um sentido de utilidade do novo currículo para com a comunidade e essa realizar-se-ia pela concretização de um «Teatro Lyrico», agilizado pela abertura duma disciplina de italiano. Euterpe seria uma diva lírica, mas poderia também incarnar qualquer membro da orquestra, ou até do coro.

Gera-se cada vez mais controle, que vai ao ponto de verificar idades limites e métodos de ensino, ao mesmo tempo que se introduzem medidas, no campo da avaliação tendentes a aplacar as «muitas reclamações», que se verificavam com 
relação à constituição dos júris de exame. Passavam a integrar já não «apenas professores de Conservatorio», «fazendo entrar nelles alguns membros dos conselhos de arte musical [...] e até elementos completamente estranhos». Procura-se manter intacta a virtude de Euterpe, mas como logo denunciará Rey Colaço, eminente professor de Piano da instituição, a breve trecho se abriu caminho para introduzir ainda mais facilmente o favor social, materializado nas «cartas de empenho» dos pais que procuravam um benefício para os seus educandos ${ }^{26}$.

E se Euterpe fosse pobre, ou muito rica, ou não pudesse frequentar o Conservatório? O decreto prevê todas estas situações, e procura garantir o financiamento de estudantes necessitados, ao mesmo tempo que institui mecanismos de controlo dos professores particulares. Nada parecia escapar às malhas cada vez mais apertadas da legislação, e embora nem tudo se tenha concretizado, vigora o princípio de que Euterpe nunca poderia ser desprovida de cultura, vulgar, fútil ou meramente tecnicista. Para isso se criam novas disciplinas, como história da música. Contratam-se novos professores para prover essas disciplinas e também monitoras para vigiar a massa feminina de alunas que começa a ser demais para o edifício.

Com efeito, embora sem dispor de números concretos para todos os ramos, verifica-se a crescente difusão do ensino e o crescimento da mole de alunos que desejavam seguir uma aprendizagem formal da música. Se no ensino primário ainda tudo permanecia bastante estagnado, o Decreto de 24 de dezembro de I90 I reitera o plano inicialmente traçado vinte anos atrás para o magistério primário abrangia, com «Noções rudimentares de música, execução de coros», colocado em ação pelos publicados em 1902 (I8 de outubro e 4 de dezembro).

Com o advento da República, em outubro de I9Io, novas condições de possibilidade são concedidas às artes liberais e é um grupo de intelectuais que redige a Reforma decretada em 1919, para o Conservatório Nacional de Música, dirigido pelo reputado pianista de carreira internacional José Viana da Mota. Regressa-se à virtuosidade pianística e irrompe o medo de uma pequena Euterpe impreparada, inculta, imagem que nenhum governo assumiria. Inicia-se nesta época, de modo plenamente assumido, a elitização do ensino musical, há muito reclamada. Para tanto, foram previstas três medidas fundamentais: retirar o ensino de solfejo do conservatório, de modo a aliviar da instituição uma parte significativa de alunos, que transitariam para escolas primárias de música; consagrar a virtuosidade através da introdução de um ano suplementar; e introduzir a cultura musical, passando o conservatório a ter 32 disciplinas, incluindo «disciplinas auxiliares», de dimensões de cultura geral.

\footnotetext{
${ }^{26}$ Denunciou a pressão social a que os professores, lobrigados na constituição de júris, não se podiam eximir: «Muitas vezes se tem acusado injustamente os júris da Escola [de Música do Conservatório] de falta de justiça, de falta de competência e até de falta de probidade», quando não estavam, afinal, protegidos contra estas solicitações de «pessoas de todas as categorias e classes». ColaçO, A. R.: «Pelo conservatório: Os 'exames de fora' e a 'carta de empenho'», A arte musical, Lisboa, n. ${ }^{\circ}$ 376, Is ago. (1914), p. I20 (sublinhado no original).
} 
Também o Decreto 2.213, de Io de fevereiro de 1916, que acompanha assim a reforma dos programas do ensino primário estabelecida no Decreto 2.887, de 5 de dezembro de I916, garantia a cada vez mais alunas o ensino de música, estando previsto o ensino de rudimentos de piano, além do canto coral. Nas escolas femininas, onde ensino de música fora implementado quase de raiz, contam-se também escolas como o Instituto Feminino de Educação e Trabalho (1915) e o Liceu Maria Pia (1906) com ensino de canto coral. Por influência e pressão desta oferta cingida à população feminina, o canto coral acabou por ser estendido toda a população liceal por força do Decreto 4.650, de I4 de julbo de I9I8.

Perante a quantidade de alunos, o Conservatório só poderia responder com uma segmentação cada vez maior do tipo de pessoas que albergava. Logo se modificava a fórmula de admissão, que já não passava por «todos», mas por «quaisquer indivíduos, sem dependência de sexo nem de nacionalidade ${ }^{27}$, aperfeiçoando-se o sistema piramidal existente. A admissão inicial é aberta, mas a seletividade procura impedir uma massificação. Por sua vez, a constituição dos júris de exame retrocede aos professores do quadro, em reconhecimento da justeza da falência do antigo sistema. Instala-se no Conservatório uma cultura de seriedade, de erudição que pretende acolher uma almejada elite musical. Os programas introduzidos em dezembro de 1919, muito detalhados e com a repertório que abrangia peças nacionais de qualidade, são mostra do tipo de pessoa que se temia: alguém desprovido de elevação cultural.

Porém, os acontecimentos sucederam-se não exatamente como previsto. Em breve a crise no seio da República ameaçou a sua quebra e, em 1926, a ditadura militar foi instalada. Nunca existiram as escolas primárias musicais e, por isso, quando em 1930 o regime decide pela nova fusão de um Conservatório Nacional com uma secção de Teatro e outra de Música, lamenta-se uma vez mais o «excesso de população [...] determinado pelo afluxo dos alunos de solfejo», mas limita-se «a admissão ao curso superior de piano». A decisão justifica-se «não só porque as matrículas nesta disciplina são em número excessivo, mas ainda porque convém valorizar aquele curso, tornando-o verdadeiramente acessível aos de verdadeira vocação", abrindo vaga a apenas «cinquenta alunos, escolhidos entre os mais classificados» por concurso. Com efeito, voltam a ser admitidos «à frequência das disciplinas a cursos do Conservatório Nacional todos os indivíduos de ambos os sexos, portugueses ou estrangeiros», mas que «o requeiram ao inspetor» e para a inscrição em «canto ou qualquer instrumento» terão ainda de ser «previamente examinados pelo médico escolar do Conservatório, que preencherá a respetiva ficha sanitária e julgará a aptidão física dos candidatos $»^{28}$. Trata-se, a muitos níveis, de simplificar e de abreviar a proposta anterior, tornando-a politicamente menos ambiciosa e garantindo uma disciplina mais ciosa do seu corpo docente e discente.

27 Decreto 6.I29, de 25 de setembro de 1919, art. $25 .^{\circ}$.

28 Decreto I8.88I, de 25 de setembro de 1930, preâmbulo e art. $35 .^{\circ}$. 
Também no ensino primário e normal se fechava-se este ciclo com o Decreto 18.643, de I9 de julho de 1930, retificado em 7 de agosto de 1930. Nele se instituiu as escolas do magistério primário, destinadas à preparação do professorado primário, elementar e infantil, em substituição das escolas normais primárias. Toda uma ambiência desenvolve estes princípios de circunspeção e contenção. Uma vez instalada uma formação básica de música, apostava-se na sua continuidade pelos mínimos, em que os efeitos físicos e morais e cívicos estavam acima das aprendizagens musicais ${ }^{29}$. Sob este tríplice elo, a política educativa do Estado Novo, fundado em 1933, assentaria as suas premissas, tornando o canto coral obrigatório no ensino primário, secundário e ainda nas atividades da Mocidade Portuguesa ${ }^{30}$.

A crescente politização dos medos sociais não parece interferir diretamente com o ideário de Euterpe, mas começa a desvelar-se uma tentativa de prevenir o advento de um rude Pã a apoderar-se do destino de Euterpe. Sem o apoio e a vigilância do Estado, Euterpe facilmente recairia para um perfil vulgar, frívolo, culturalmente chão e civicamente vão, na melhor das hipóteses, envergando um saber técnico. Vários dispositivos, cada vez mais complexos, segmentam e moldam tipos de pessoas, operação essa essencialmente bem-sucedida entre o ensino preconizado pelo Conservatório e as formações de canto coral disponíveis para a população em geral, nas escolas primárias, e para as elites, nas escolas secundárias. Euterpe não seria uma qualquer.

\section{Discussão final}

Ao longo da centúria que decorre para a completa instalação do moderno ensino de música em Portugal, observam-se pelo menos três grandes níveis arqueológicos do currículo de educação e ensino musical. Um primeiro tempo, iniciado em I835, coincide com a fase de laicização e implantação do conservatório estatal, a partir das antigas estruturas do Conservatório da Sé Patriarcal de Lisboa. Encontramos, a longo de cerca de 30 anos um esforço por manter estas estruturas laicas, mas é com grande contenção que o conservatório se sustenta. Foi, para isso, necessário, acolher na escola oficial um público vasto, diverso nas origens sociais e nas suas intenções para com um destino comprometido profissionalmente com a música. A criança excluída deste currículo trazia a sombra do passado e temia-se que Euterpe fosse incapaz de se furtar às malhas da Igreja Católica, ao mesmo tempo que se vislumbrava uma criança num futuro temeroso, em que o Estado não mostrava a sua capacidade de conter dentro de si o dom-apesar de tudo, divino - e de devolver à sociedade crianças e jovens com promissoras

29 Ascenso, M. ${ }^{a}$ C.: «Arte na escola primária», em Lima, A. (ed.): Enciclopédia pedagógica Progredior, vol. I, Lisboa, Progredior, c. 1940, p. 1322.

3o SiLva, M.: 'La musique a besoin d'une dictature' (1926-1945), Tese de doutoramento, Paris, Université de Paris VIII, 2005; BarreIros, M. ${ }^{a}$ J. A.: A disciplina de canto coral no periodo do Estado Novo, Tese de mestrado, Lisboa, Universidade Nova de Lisboa, 1999. 
carreiras musicais. Uma pequena Euterpe cheia de talento, mas remetida para a marginalidade por falta de apoios, pesaria na consciência de toda a sociedade. Iniciava-se o culto do génio, com um destino traçado, onde Estado se mostrava como o protetor e responsável.

Num segundo tempo, ocorrem diversos deslocamentos e a pequena Euterpe que todos temem não é mais uma órfã abandonada, ou uma marginal, é alguém que vira costas ao seu destino e não é, consequentemente, educada como deveria. Reconhece-se nesta transição uma primeira demanda do génio musical como alguém que, apesar do dom inato, deve ser escolarizado, ou ter alguma educação formal em música, noutra escola ou com um professor particular. O currículo começa aqui a providenciar que, cada indivíduo à sua maneira, dentro da sua função social, seja devidamente instruído e educado. Para tanto, o Estado não tem mais uma relação direta com a infância e juventude, mas articula-se mediante processos cada vez mais burocratizados, onde esses diferentes tipos de formações - que passam também a estar sob a alçada do Real Conservatório - servem diferentes tipos de pessoas. Os medos que assolam o currículo passam pelo reconhecimento de Euterpe como um génio não-legítimo, chegando a instalar-se a «sorte» como mecanismo no sistema de avaliação, de tal modo se pretendia afastar a possibilidade de o favor social obstruir o caminho do verdadeiro génio em favor dos mais beneficiados socialmente.

No terceiro e último tempo, percorrendo as primeiras três décadas do século Xx, o grande medo de uma pequena Euterpe amplia ainda o reconhecimento das desigualdades sociais e o currículo responde, sem dúvida, a uma inquietação que vinha crescendo desde a década de i840: e se Euterpe, apesar da educação e instrução, não for genial? Aprofundando os diferentes tipos de resposta através de múltiplas formações, o currículo começa, assim, a responder com medidas de elitização que buscavam garantir que só os mais dotados alcançassem os níveis de topo da formação artística e a possibilidade do exercício profissional. Não bastava saber música, era preciso que o currículo garantisse o respaldo cultural, e uma distinção entre quem é e quem não é verdadeiramente artista se fizesse notar. Este modo de organizar o currículo dependia em muito das diferentes camadas que, entretanto, se tinham formado com o alargamento de alguma cultura musical, muito incipiente, expandida pelo ensino primário, secundário e normal. Euterpe reinaria, mas apenas se fosse genial. E como todos bem sabiam, muito frequentemente, não o era.

Nestas diferentes temporalidades, a historicização da criança do futuro mostra que existe um evidente paralelismo entre as diferentes modalidades de formação musical que se desenvolvem numa época, pois elas situam-se numa semelhante racionalidade. Neste sentido, parece possível afrontar o currículo em música muito para lá de diferenciações institucionais e ramificações, que mais não fazem do que operar como dispositivos de segmentação de pessoas que, na realidade, se imiscuem num mesmo devir adulto, atendendo aos mesmos desejos e medos sociais que o Estado centraliza e toma para si. 
